\title{
Nausea-Induced 5-HT Release in the Interoceptive Insular Cortex and Regulation by Monoacylglycerol Lipase (MAGL) Inhibition and Cannabidiol
}

\author{
Cheryl L. Limebeer, ${ }^{1}$ Erin M. Rock, ${ }^{1}$ Keith A. Sharkey, ${ }^{2}$ and Linda A. Parker ${ }^{1}$
}

DOI:http://dx.doi.org/10.1523/ENEURO.0256-18.2018

${ }^{1}$ Department of Psychology and Neuroscience Program, University of Guelph, Guelph, Ontario N1G 2W1, Canada and ${ }^{2}$ Hotchkiss Brain Institute, Department of Physiology and Pharmacology, University of Calgary, Calgary, Alberta T2N 4N1, Canada

\begin{abstract}
Using the rat conditioned gaping model of nausea, the interoceptive insular cortex (IIC) has been identified as a critical site for the regulation of lithium chloride ( $\mathrm{LiCl}$ )-induced nausea. Indirect evidence supports a model where serotonin $(5-\mathrm{HT})$ acts on postsynaptic $5-\mathrm{HT}_{3}$ receptors and its release is suppressed by elevating 2-arachidonylglycerol (2-AG) by monoacylglycerol lipase (MAGL) inhibition to suppress nausea. Here, we directly test the hypothesis that systemic $\mathrm{LiCl}$ elevates $5-\mathrm{HT}$ in the IIC, and this is prevented by pretreatments that reduce 5-HT release. Using male Sprague Dawley rats, LiCl (but not saline), elevated 5-HT selectively in the IIC, for $20 \mathrm{~min}$ after LiCl administration (127.2 mg/kg, i.p.). Systemic pretreatment with the MAGL inhibitor, MJN110, prevented the LiCl-induced elevation of 5-HT in the IIC. Systemic cannabidiol (CBD), which reduces $\mathrm{LiCl}$-induced nausea by acting at 5- $\mathrm{HT}_{1 \mathrm{~A}}$ somatodendritic autoreceptors, also prevented $\mathrm{LiCl}$-induced elevation of $5-\mathrm{HT}$ in the IIC. Since 5- $\mathrm{HT}_{3}$ receptor agonists delivered to the IIC produce nausea, we tested and confirmed the hypothesis that the intra-IIC administration of $5-\mathrm{HT}_{3}$ receptor antagonist, ondansetron, but not MJN110, would prevent LiCl-induced conditioned gaping reactions produced by intra-IIC administration of the $5-\mathrm{HT}_{3}$ receptor agonist, $m$-chlorophenylbiguanide (mCPBG). Finally, we demonstrate that exposure to a LiCl-paired flavor (but not a saline-paired flavor) produces elevated 5-HT release in the IIC, while rats display conditioned gaping reactions. These results confirm that $\mathrm{LiCl}$-induced nausea is triggered by elevated 5- $\mathrm{HT}$ release in the IIC and is attenuated by treatments that reduce 5-HT availability in this region.
\end{abstract}

Key words: cannabinoid; interoceptive insular cortex; microdialysis; nausea; rat; serotonin

\section{Significance Statement}

Understanding of the neurobiology of nausea has lagged behind that of the neurobiology of vomiting. Here we demonstrate for the first time that a nauseating drug produces an elevation of serotonin in the brain region that mediates nausea in humans, the interoceptive insular cortex (IIC). This elevated serotonin (and nausea) is prevented by pretreatment with a drug that elevates the endocannabinoid (eCB), 2-arachidonylglycerol (2-AG), in this region. As well, pretreatment with the non-psychoactive cannabinoid, cannabidiol, acts to reduce forebrain release of serotonin (and nausea) triggered by the nauseating drug. These results strongly suggest serotonin serves as a trigger to produce the sensation of nausea in the IIC and cannabinoids act to prevent this trigger to regulate nausea.

\section{Introduction}

While current anti-emetic therapies are highly effective in reducing vomiting, they are less effective in treating chemotherapy-induced nausea (Hickok et al., 2003; Fou-

Received June 29, 2018; accepted July 3, 2018; First published July 30, 2018.

The authors declare no competing financial interests. bert and Vaessen, 2005; Ballatori et al., 2007), because of a poor understanding of the neurobiology of nausea. We have demonstrated that conditioned gaping elicited by a

Author Contributions: C.L.L., E.M.R., L.A.P., and K.A.S. designed research; C.L.L., E.M.R., and L.A.P. performed research; C.L.L., E.M.R., and L.A.P. analyzed data; C.L.L., E.M.R., L.A.P., and K.A.S. wrote the paper. 
nausea-paired taste in the taste reactivity test in the rat (initially identified by Grill and Norgren, 1978) is a highly selective model of nausea and have used it to explore the neural circuits involved in the regulation of nausea, including serotonergic (5-HT) and endocannabinoid (eCB) mechanisms (Parker, 2014).

The insular cortex (IC) is a critical region for generating the sensations of nausea (Penfield and Faulk, 1955; Kiefer and Orr, 1992; Contreras et al., 2007; Napadow et al., 2013; Sclocco et al., 2016) and disgust (Calder et al., $2000,2001)$. Electrophysiological and anatomic studies in rats have determined that the $\mathrm{IC}$ is the cortical site of topographical input of visceral (posterior granular or interoceptive IC; IIC) and gustatory input (anterior dysgranular or gustatory IC; GIC) and their convergence (agranular IC; Cechetto and Saper, 1987; Hamilton and Norgren, 1984; Kosar et al., 1986; Allen et al., 1991). Growing evidence suggests that elevated 5-HT in the IIC triggers nausea and treatments that reduce 5-HT in the IIC suppress nausea. In a double dissociation study, we found that intracranial administration of the $5-\mathrm{HT}_{3}$ receptor antagonist, ondansetron, into the IIC attenuated lithium chloride ( $\mathrm{LiCl}$ )-induced conditioned gaping, but not taste avoidance (Tuerke et al., 2012a). Conversely, ondansetron delivered into the GIC attenuated $\mathrm{LiCl}$-induced taste avoidance, but not conditioned gaping. Direct delivery of a $5-\mathrm{HT}_{3}$ receptor agonist into these regions produced the opposite effect and produced nausea on its own in the IIC. These data provide strong evidence that serotonergic input to the IIC is necessary for the production of nausea-induced conditioned gaping. Here, we evaluate the hypothesis that systemic $\mathrm{LiCl}$ elevates $5-\mathrm{HT}$ in the IIC and this is prevented by pretreatments that reduce $5-\mathrm{HT}$ release by directly measuring $5-\mathrm{HT}$ release in the IIC during episodes of $\mathrm{LiCl}$-induced nausea.

The anti-nausea effects of cannabinoids (Sticht et al., 2016) and treatments that reduce the release of $5-\mathrm{HT}$, such as cannabidiol (CBD), cannabidiolic acid (CBDA), and 8-hydroxy-2-(di-npropylamino) tetralin (8-OH-DPAT; Limebeer and Parker, 2003; Rock et al., 2012; Bolognini et al., 2013), may be mediated by their action in the IIC. There is considerable evidence that $\mathrm{CB}_{1}$ receptors are localized on presynaptic terminal endings of 5-HT releasing neurons (Häring et al., 2007, 2013); therefore, it is possible that activation of $\mathrm{CB}_{1}$ receptors in the IIC suppresses the release of nausea-inducing $5-\mathrm{HT}$. The potent cannabinoid agonist, $\mathrm{HU}-210$, delivered into the IIC (but

This work was supported by Canadian Institutes of Health Research Grants (CIHR 388239, 340889, 323932) and by the Natural Sciences and Engineering Research Council of Canada Grant 03629 (to L.A.P.).

Acknowledgements: We thank the late Larry Parsons, Scripps Institute, LaJolla, for his guidance in in-vivo microdialysis/HPLC measurement of serotonin.

Correspondence should be addressed to Linda A. Parker, Department of Psychology and Neuroscience Program, University of Guelph, Guelph, Ontario N1G 2W1, Canada, E-mail: parkerl@uoguelph.ca.

DOI:http://dx.doi.org/10.1523/ENEURO.0256-18.2018

Copyright (C) 2018 Limebeer et al.

This is an open-access article distributed under the terms of the Creative Commons Attribution 4.0 International license, which permits unrestricted use, distribution and reproduction in any medium provided that the original work is properly attributed. not the $\mathrm{GIC}$ ), reduced $\mathrm{LiCl}$-induced conditioned gaping reactions by a $\mathrm{CB}_{1}$ receptor mechanism (Limebeer et al., 2012). More recently, we found that selective elevation of the eCB, 2-arachidonylglycerol (2-AG), but not anandamide (AEA), in the IIC, by pretreatment with the monoacylglycerol lipase (MAGL) inhibitor, MJN110, reduced $\mathrm{LiCl}$-induced conditioned gaping, by a $\mathrm{CB}_{1}$ receptor mechanism of action (Sticht et al., 2016). As well, 2-AG (but not AEA) is elevated and c-fos is activated in the IIC during an acute episode of $\mathrm{LiCl}$-induced nausea. CBD, CBDA, and 8-OH-DPAT all reduce nausea-induced conditioned gaping by acting at somatodendritic 5- $\mathrm{HT}_{1 \mathrm{~A}}$ autoreceptors in the dorsal raphe nucleus (Rock et al., 2012); this action results in reduced firing of 5-HT afferent neurons and a corresponding decrease in the release of 5-HT in terminal regions (Verge et al., 1985; Blier and de Montigny, 1987). Therefore, we predict that MJN110 and CBD will reduce the elevation in 5-HT in the IIC which triggers LiCl-induced nausea. Although MJN110 is predicted to reduce $\mathrm{LiCl}$-induced release of $5-\mathrm{HT}$, it would not be expected to interfere with the nausea produced by an agonist of postsynaptic $5-\mathrm{HT}_{3}$ receptors delivered to the IIC. Finally, we evaluate whether exposure to a $\mathrm{LiCl}-$ paired flavor will conditionally elevate 5-HT in the IIC.

\section{Materials and Methods}

\section{Subjects}

A total of 147 male Sprague Dawley rats were obtained from Charles River Canada and pair-housed in polycarbonate cages $(44 \times 25 \times 21 \mathrm{~cm})$, with Bed-0'Cobs bedding on the floor of the cage. Subjects were provided with food pellets (Highland Rat Chow) and water ad libitum. The animal quarters were kept on a reversed 12/12 $\mathrm{h}$ light/dark cycle (lights on from 7 P.M. to 7 A.M.) and maintained at $22 \pm 2{ }^{\circ} \mathrm{C}$ and $45 \pm 20 \%$ relative humidity. All animals were handled before testing and the guidelines set out by the Canadian Council on Animal Care Committee and the Animals for Research Act were followed. The experiments were approved by the University of Guelph Animal Care Committee.

\section{Drugs}

Drugs were administered systemically, by intraperitoneal injection, or intracranially into the IIC. $\mathrm{LiCl}$ was used as the nausea-inducing agent, at a dose of $127.2 \mathrm{mg} / \mathrm{kg}$ (20 $\mathrm{ml} / \mathrm{kg}$ of $0.15 \mathrm{M}$ solution), the optimal dose for inducing conditioned gaping (Zalaquett and Parker, 1989). LiCl, the standard nausea-inducing drug (Garcia et al., 1974), is a relatively non-toxic compound producing malaise for 45 min and can be chronically administered (Tuerke et al., 2012b). Control groups for $\mathrm{LiCl}$ were injected with an equal volume saline as vehicle (VEH) controls. MJN110 and CBD were prepared in a VEH consisting of a 1:1:18 mixture of ethanol:Tween 80:saline. MJN110 or CBD were first dissolved in ethanol in a graduated cylinder, then Tween 80 is added to the solution and the ethanol is evaporated off with a nitrogen stream after the saline is added. The final VEH consisted of 1:9 (Tween:saline) which was used as the VEH control for the MJN110 and the CBD pretreatments. For systemic administration, the 
dose of MJN110 was $10 \mathrm{mg} / \mathrm{kg}$ (Parker et al., 2015; Sticht et al., 2016) administered at a volume of $1 \mathrm{ml} / \mathrm{kg}$, for intracranial administration the dose of MJN110 was 2 $\mu \mathrm{g} / \mu \mathrm{l}$ and microinfused into the IIC at $0.5 \mu \mathrm{l} / \mathrm{min}$ for $2 \mathrm{~min}$ (Sticht et al., 2016). The dose of CBD was $5 \mathrm{mg} / \mathrm{kg}$ administered at a volume of $1 \mathrm{ml} / \mathrm{kg}$ (Rock et al., 2012). The $5-\mathrm{HT}_{3}$ agonist, $m$-chlorophenylbiguanide (mCPBG) and the $5-\mathrm{HT}_{3}$ antagonist, ondansetron, were prepared for intracranial administration in sterile saline solution at concentrations of 30 and $0.1 \mu \mathrm{g} / \mu \mathrm{l}$, respectively (Tuerke et al., 2012a). They were both infused at a rate of $0.5 \mu \mathrm{l} / \mathrm{min}$ for 2 min.

\section{Surgical procedures}

In experiments 1 and 3 , the rats were implanted with a unilateral and in experiment 2 with bilateral indwelling guide cannulae into the IIC (region of interest), or into the GIC (control region), while under isoflurane anesthesia for later insertion of a microdialysis probe. The stereotaxic surgery procedure has been previously described (Tuerke et al., 2012a). The guide cannula (21 gauge, $6 \mathrm{~mm}$ below pedestal) was set at a divergent $10^{\circ}$ angle and lowered into the IIC using the following coordinates from bregma: $-0.5 \mathrm{~mm} \mathrm{AP,} 5.0 \mathrm{~mm} \mathrm{ML},-4.5 \mathrm{~mm}$ DV (Contreras et al., 2007); half of the rats received cannulae in the left hemisphere and half in the right hemisphere. A control experiment evaluated microdialysis samples taken from the GIC (from bregma: $+2.5 \mathrm{~mm} \mathrm{AP,} 5.0 \mathrm{~mm} \mathrm{ML},-4.5 \mathrm{~mm} \mathrm{DV}$ ), which we have shown is not involved in nausea-induced gaping (Limebeer et al., 2012; Tuerke et al., 2012a). In experiments 2 and 3 , on the day of intracranial surgery, rats were also implanted with an intraoral cannula for the oral delivery of the saccharin solution in the taste reactivity conditioning/testing trials according to the procedure previously described by Limebeer et al. (2012).

\section{Histology}

Guide cannulae placements were evaluated by histology. Rats were deeply anaesthetized using an $85 \mathrm{mg} / \mathrm{kg}$ injection of Euthansol (Intervet Canada Corp.) followed by transcardial perfusion with phosphate buffered saline (0.1 $\mathrm{M})$ and $4 \%$ formalin. The brains were removed and stored at $4^{\circ} \mathrm{C}$ in $4 \%$ formalin solution for $24-48 \mathrm{~h}$ after which they were placed in a $20 \%$ sucrose solution overnight at room temperature. The brains were then sliced in $60-\mu \mathrm{m}$ sections using a CM1850 Leica cryostat and relevant sections were mounted on glass microscope slides. The tissue was stained with cresyl violet $24 \mathrm{~h}$ later and examined for accurate cannula placement using a Leica MZ6 Stereomicroscope with a Leica DFC420 Digital Camera and Leica Application Suite software. Rats with improper cannula placements, such as those located outside of the target region were excluded from the behavioural analyses. All reported group n's refer to the rats with verified cannulae placements. Accurate IIC placements were between -0.24 and $-0.72 \mathrm{~mm}$ posterior of bregma. A representative photomicrograph of an IIC (the region of interest) placed probe is presented in Figure 1. Accurate GIC placements (control region) were between 1.68 and $1.20 \mathrm{~mm}$ anterior to bregma. A total of 21 rats had mis- placed cannulae in the reported experiments; therefore the total number of rats included in the analyses was 126 .

\section{In vivo microdialysis and HPLC detection of 5-HT}

The microdialysis probes consist of $2.5 \mathrm{~mm}$ in length of semipermeable dialysis membrane from Spectra/Por in vivo Microdialysis Hollow Fibers, $2 \mu \mathrm{m}$ OD, 13,000 MW cutoff. On the day of sampling, a microdialysis probe was inserted into the guide cannula directed to the IIC or the GIC. Artificial CSF (aCSF; $147 \mathrm{mM} \mathrm{NaCl}, 2.8 \mathrm{mM} \mathrm{KCl}, 1.2$ $\mathrm{mM} \mathrm{CaCl}$, and $1.2 \mathrm{mM} \mathrm{MgCl}_{2} ; \mathrm{pH} 7.4$ ) was perfused at a rate of $0.6 \mu \mathrm{l} / \mathrm{min}$ for a period of $300 \mathrm{~min}$, after an acclimatization of $120 \mathrm{~min}$, samples were collected and frozen on dry ice every $20 \mathrm{~min}$ for a total of $300 \mathrm{~min}$.

The dialysate from the samples were analyzed for $5-\mathrm{HT}$ using the Eicom HTEC-510 HPLC/ECD system (Eicom USA). Each sample was extracted from the vial and loaded on a C-18 reverse-phase column (PP-ODS II, 4.6 $\times 30 \mathrm{~mm}$, Eicom USA) using a manual injection port (Rheodyne 9725i; 20- $\mu$ l loop). The column was maintained at a temperature of $25^{\circ} \mathrm{C}$ with a mobile phase [0.1 $\mathrm{M}$ phosphate buffer $\mathrm{pH} 5.4$, including 1.5\% methanol, 500 $\mathrm{mg} / \mathrm{l}$ decansulfonate sodium salt (DSS), and $50 \mathrm{mg} / \mathrm{l} 2 \mathrm{Na}-$ EDTA] set at a flow rate of $0.6 \mu \mathrm{l} / \mathrm{min}$. Electrochemical detection of 5-HT was determined using a graphite working electrode (WE-3G, Eicom USA) maintained at a potential of $+450 \mathrm{mV}$ relative to an $\mathrm{Ag} / \mathrm{AgCl}$ reference electrode (RE-500, Eicom USA).

\section{Behavioral procedures}

Experiment 1: effect of $\mathrm{LiCl}$ on 5-HT release in the IIC or GIC (control area) and effect of pretreatments with

MJN110 or CBD

On the day of sampling, rats were placed into the opaque black Plexiglas microdialysis chambers $(60 \times 40 \times 40 \mathrm{~cm})$ with Bed-0'Cobs bedding on the plastic floors. A microdialysis probe was inserted into the guide cannula directed to the IIC or the GIC and aCSF was perfused at a rate of 0.6 $\mu \mathrm{l} / \mathrm{min}$. After an acclimatization of $120 \mathrm{~min}$, baseline samples were collected and frozen every $20 \mathrm{~min}$ for $60 \mathrm{~min}$. These three measures served as the baseline measures to be used in the analyses. To compare the subsequent effects of pretreatment with MJN110 and CBD in subsequent experiments, the rats were then injected with the VEH (1:9 Tween 80:saline) $1 \mathrm{~h}$ before receiving either $\mathrm{LiCl}(n=10$ in IIC, $n=$ 7 in GIC) or saline ( $n=10$ in IIC, $n=7$ in GIC). Samples continued to be collected every $20 \mathrm{~min}$ for $240 \mathrm{~min}$ after the pretreatment (VEH) injection.

Once it was determined that $\mathrm{LiCl}$ elevated $5-\mathrm{HT}$ in the IIC, the effect of pretreatment with MJN110 or CBD $1 \mathrm{~h}$ before receiving either $\mathrm{LiCl}$ or saline on the elevation of $5-\mathrm{HT}$ in the IIC produced by $\mathrm{LiCl}$ was determined. The following groups were evaluated: MJN saline $(n=11)$, MJN LiCl $(n=11)$, CBD saline (10), CBD LiCl (9), and compared with the previously collected groups VEHsaline $(n=11)$ and VEH-LiCl $(n=9)$.

Experiment 2: effect of MJN110 or ondansetron in the IIC on conditioned gaping elicited by IIC infusion of 5- $\mathrm{HT}_{3}$ receptor agonist $\mathrm{mCPBG}$

Tuerke et al. (2012a) demonstrated that activation of the postsynaptic $5-\mathrm{HT}_{3}$ neurons in the IIC during saccharin- $\mathrm{LiCl}$ 

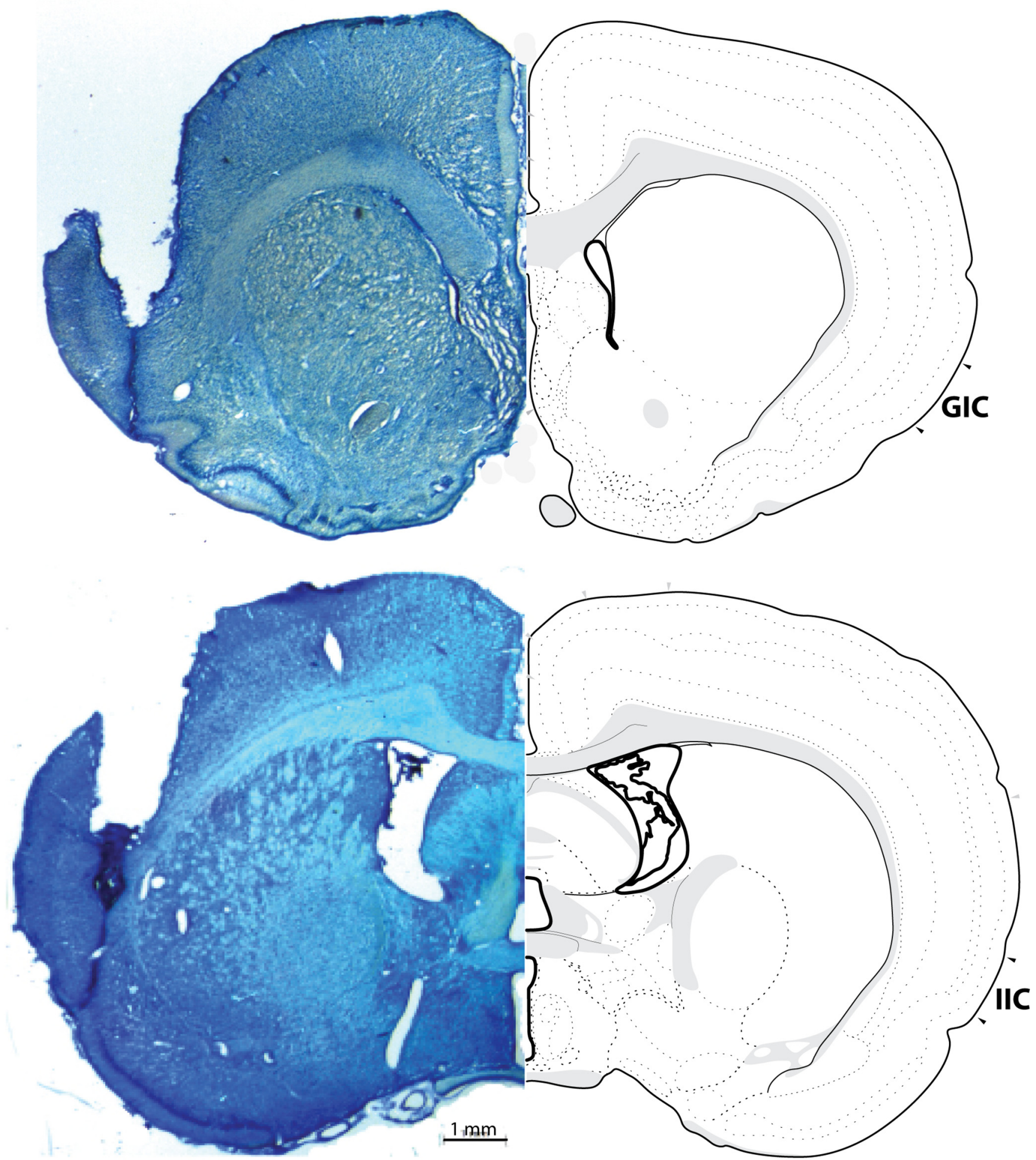

Figure 1. Representative photomicrograph of probe placement into the GIC and the IIC. Accurate GIC (control region) placements were between 1.68 and $1.20 \mathrm{~mm}$ anterior to bregma. Accurate IIC placements were between -0.24 and $-0.72 \mathrm{~mm}$ posterior of bregma.

conditioning is critical for the development of conditioned gaping reactions. If MAGL inhibition-induced elevated 2-AG acts to reduce nausea by reducing $\mathrm{LiCl}$-induced release of $5-\mathrm{HT}$ in the IIC, then MJN110 should not prevent gaping produced by an IIC infusion of the $5-\mathrm{HT}_{3}$ receptor agonist
mCPBG. On the other hand, ondansetron administration in the IIC should prevent $\mathrm{mCPBG}$-induced conditioned gaping, because it blocks postsynaptic $5-\mathrm{HT}_{3}$ receptors. To test this hypothesis, during each of two conditioning trials, rats were infused in the IIC with VEH, MJN110 $(2 \mu \mathrm{g} / \mu \mathrm{l})$, or OND $(0.1$ 
$\mu \mathrm{g} / \mu \mathrm{l})$ bilaterally and $1 \mathrm{~h}$ later, they received a pairing of saccharin with IIC infusion of mCPBG (30 $\mu \mathrm{g} / \mu \mathrm{l})$, which produces conditioned gaping (Tuerke et al., 2012a).

Following recovery from surgery, rats were placed in the taste reactivity apparatus (see Tuerke et al., 2012a for procedural details) with their intraoral cannuale attached to an infusion pump to allow intraoral delivery of fluid across their tongue. Following $3 \mathrm{~min}$ in the taste reactivity chamber, the rats were infused with water at the rate of 1 $\mathrm{ml} / \mathrm{min}$ for $3 \mathrm{~min}$. Twenty-four hours after the adaptation trial, the rats received two conditioning trials spaced $72 \mathrm{~h}$ apart followed by a drug free test trial $72 \mathrm{~h}$ later. These trials were identical to the adaptation trial, except that the rats were intraorally infused with $0.1 \%$ saccharin solution instead of water and their orofacial and somatic responses were recorded from a mirror beneath the chamber. An observer who was blind to the experimental condition of the rat scored the orofacial and somatic responses using The Observer (Noldus Information Technology Inc.). The groups were randomly assigned to VEHsaline $(n=10)$, VEH-mCPBG $(n=10)$, MJN110-mCPBG $(n=8)$, OND-mCPBG $(n=10)$. MJN110 pretreatment was administered 60 min before each conditioning trial, whereas all other pretreatments were administered immediately before conditioning trials 1 and 2 (Tuerke et al., 2012a). Immediately following the saccharin infusion, each rat was microinfused with $\mathrm{mCPBG}$ or saline into the IIC. Following all microinfusions, the injector which extends $2 \mathrm{~mm}$ below the tip of the guide cannula, was left in place for $1 \mathrm{~min}$. Following the test trial, the rats were perfused and the brains removed for histologic examination. An observer who was blind to the experimental condition of the rat scored the recorded tapes for the frequency of gaping reactions (wide open triangular shaped mouth revealing incisors) using The Observer (Noldus Information Technology Inc.).

Experiment 3: effect of exposure to a LiCl-paired saccharin solution on 5-HT release in the IIC

Experiment 3 evaluated the potential of exposure to a $\mathrm{LiCl}$-paired flavor to elicit elevated 5-HT in the IIC, when they were gaping in the microdialysis chambers. To ensure that the rats would maintain gaping reactions to the $\mathrm{LiCl}$-paired saccharin solution across the 20-min test, they were given three conditioning trials before testing. To prevent the establishment of an association between the taste reactivity chambers and $\mathrm{LiCl}$-induced nausea, the rats received a total of four daily adaptation trials to the chambers during which their intraoral cannulae were attached to the infusion pump (Model KDS100, KD Scientific) and they were infused with water at the rate of 1 $\mathrm{ml} / \mathrm{min}$ for $2 \mathrm{~min}$. Following the adaptation trial, the rats were conditioned every $72 \mathrm{~h}$. On each conditioning trial, the rat was placed in the taste reactivity chamber for $1 \mathrm{~min}$ and then was infused with $0.1 \%$ saccharin solution ( 1 $\mathrm{ml} / \mathrm{min}$ ) for 2 min followed immediately by an intraperitoneal injection of $\mathrm{LiCl}(n=7)$ or saline $(n=6)$. To ensure equal exposure to the experience of illness, rats received non-contingent home cage injections (24 h after conditioning trial 1 and $24 \mathrm{~h}$ before each of conditioning trials 2 and 3) such that the $\mathrm{LiCl}$-conditioned rats received saline and the saline-conditioned rats received $\mathrm{LiCl}$.

Ninety-six hours after the final taste reactivity conditioning trial, the rats were given the drug-free taste reactivity test trial in the microdialysis chambers with a clear glass floor in place of the plastic floor with bedding. Before placement in the chambers, microdialysis probes were inserted into the guide cannula directed to the IIC and aCSF was infused at the rate of $0.6 \mu \mathrm{l} / \mathrm{min}$. After an acclimatization of $120 \mathrm{~min}$, baseline samples were collected and frozen every $20 \mathrm{~min}$ for $120 \mathrm{~min}$. These six measures served as the baseline measures to be used in the analyses. Then the intraoral cannula was attached to the infusion pump and the rat was intraorally infused with saccharin solution for $20 \mathrm{~min}$ at the rate of $0.5 \mathrm{ml} / \mathrm{min}$. Its orofacial and somatic reactions were recorded during the test trial from a mirror at a $45^{\circ}$ angle beneath the microdialysis chamber. The tapes were later scored for gaping reactions (wide open triangular mouth with bottom incisors exposed). Additionally, seconds of active locomotion (forward movement in the chamber) and rearing (both paws off the floor of the cage) were summed as a total activity measure.

\section{Experimental design and statistics}

The concentration of 5-HT in the dialysate samples was converted to percentage baseline (determined by the mean $\mathrm{pg} / \mu \mathrm{l}$ of the last three baseline readings before injection 1 in experiments 1 and 2 and the mean $\mathrm{pg} / \mu \mathrm{l}$ of the six baseline readings before saccharin infusion in experiment 3) entered into mixed factor ANOVAs with the within group factor of time of sample (a total of 15). First, the effect of $\mathrm{LiCl}$ on elevation of $5-\mathrm{HT}$ in the IIC or the GIC was separately analyzed as a 2 (treatment: $\mathrm{LiCl}$ or saline treatment) $\times 15$ (time measures) factors ANOVA. Then the this baseline response was compared with groups that received pretreatments in a 3 (pretreatment) $\times 2$ (treatment) $\times 15$ (time measures) mixed factors ANOVA. In experiment 2 , the number of gapes displayed by each rat during both conditioning trials and the test trial was entered into a 4 (group: VEH-VEH, VEH-mCPBG, ONDmCPBG, MJN-mCPBG) $\times 3$ (trial: C1, C2, test) mixed factor ANOVA. Finally, to determine whether LiCl-paired saccharin would conditionally elevate $5-\mathrm{HT}$ in the IIC, the percentage baseline 5-HT measures were entered into a 2 (conditioning group: Sac-> $\mathrm{LiCl}$ or Sac->saline) $\times 15$ (time) mixed factors ANOVA. As well the number of gapes and number of seconds displaying total activity (active locomotion and rearing combined) were analyzed by independent $t$ tests. Post hoc Tukey HSD tests were used when appropriate.

\section{Results}

\section{Experiment 1: effect of $\mathrm{LiCl}$ on $5-\mathrm{HT}$ release in the IIC or GIC and effect of pretreatments with MJN110 or CBD}

$\mathrm{LiCl}$ treatment elevated 5-HT in the IIC, but not the GIC, for the first 20-min period of dialysate collection. Figure 2 presents the mean $( \pm$ SEM) percentage of baseline $5-\mathrm{HT}$ during each 20-min collection period in the IIC (1a) and in 


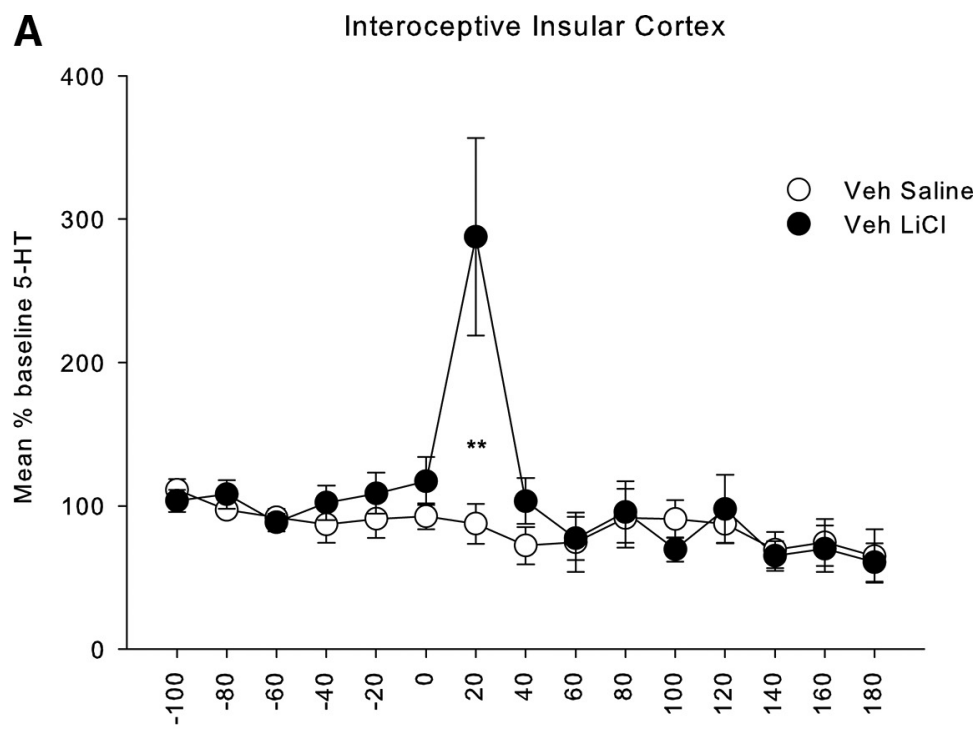

B Gustatory Insular Cortex

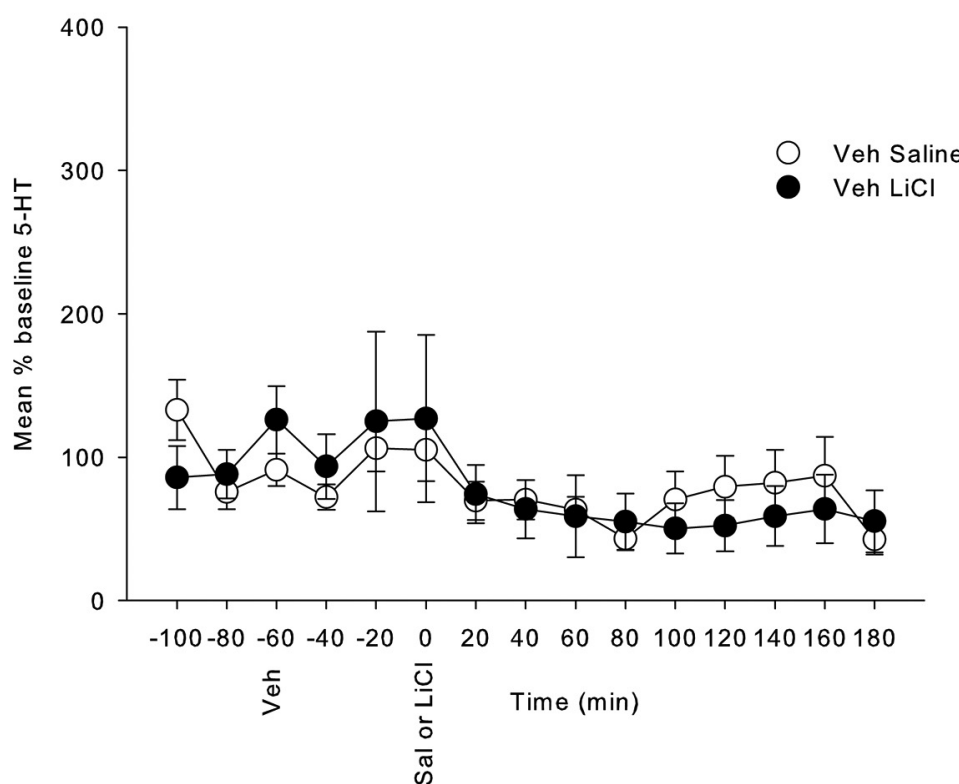

Figure 2. Mean ( \pm SEM) \% baseline $5-\mathrm{HT}$ in rats with microdialysis probes placed in the $(\boldsymbol{A})$ IIC and in the $(\boldsymbol{B})$ GIC. Following 120 min of acclimatization, samples were collected every $20 \mathrm{~min}$ for a total of $300 \mathrm{~min}$; the first three samples served as the baseline samples which were used to convert each score into a \% baseline measure. The rats were injected intraperitoneally with a VEH immediately following the final baseline measure and with equivolume $\mathrm{LiCl}(127.2 \mathrm{mg} / \mathrm{kg}$, i.p.) or saline 60 min later. Stars indicate a significant difference between $\mathrm{LiCl}$ and saline, $* * p<0.025$.

the GIC (1b). The $2 \times 15$ mixed factors ANOVA for the percentage of baseline 5-HT in the IIC revealed a significant main effect of time, $F_{(14,252)}=5.2 ; p<0.001$ and a significant group by time interaction, $F_{(14,252)}=4.1 ; p<$ 0.001 . Subsequent comparison tests revealed that the only interval that the groups differed was during the first 20 min after injection $(p<0.025)$. On the other hand, the $2 \times 15$ mixed factors ANOVA for the percentage of baseline 5-HT in the GIC revealed only a significant main effect of time, $F_{(14,168)}=2.7 ; p<0.01$, but no effects of group.
Both MJN110 and CBD pretreatment reduced the release of $5-\mathrm{HT}$ during the first $20 \mathrm{~min}$ after $\mathrm{LiCl}$. Figure 3 presents the mean $( \pm$ SEM) percentage of baseline $5-\mathrm{HT}$ during each 20-min collection period for the VEH, MJN110, and CBD pretreatment groups. The mixed factors ANOVA revealed a significant main effect of time, $F_{(14,770)}=5.4 ; p<0.001$, pretreatment $\times$ time interaction, $F_{(28,770)}=3.1 ; p<0.001$, treatment $\times$ time interaction, $F_{(14,770)}=2.2 ; p<0.01$, and pretreatment $\times$ treatment $\times$ time interacton, $F_{(28,770)}=2.4 ; p<0.001$. The three-way interaction was subsequently evaluated by conducting 

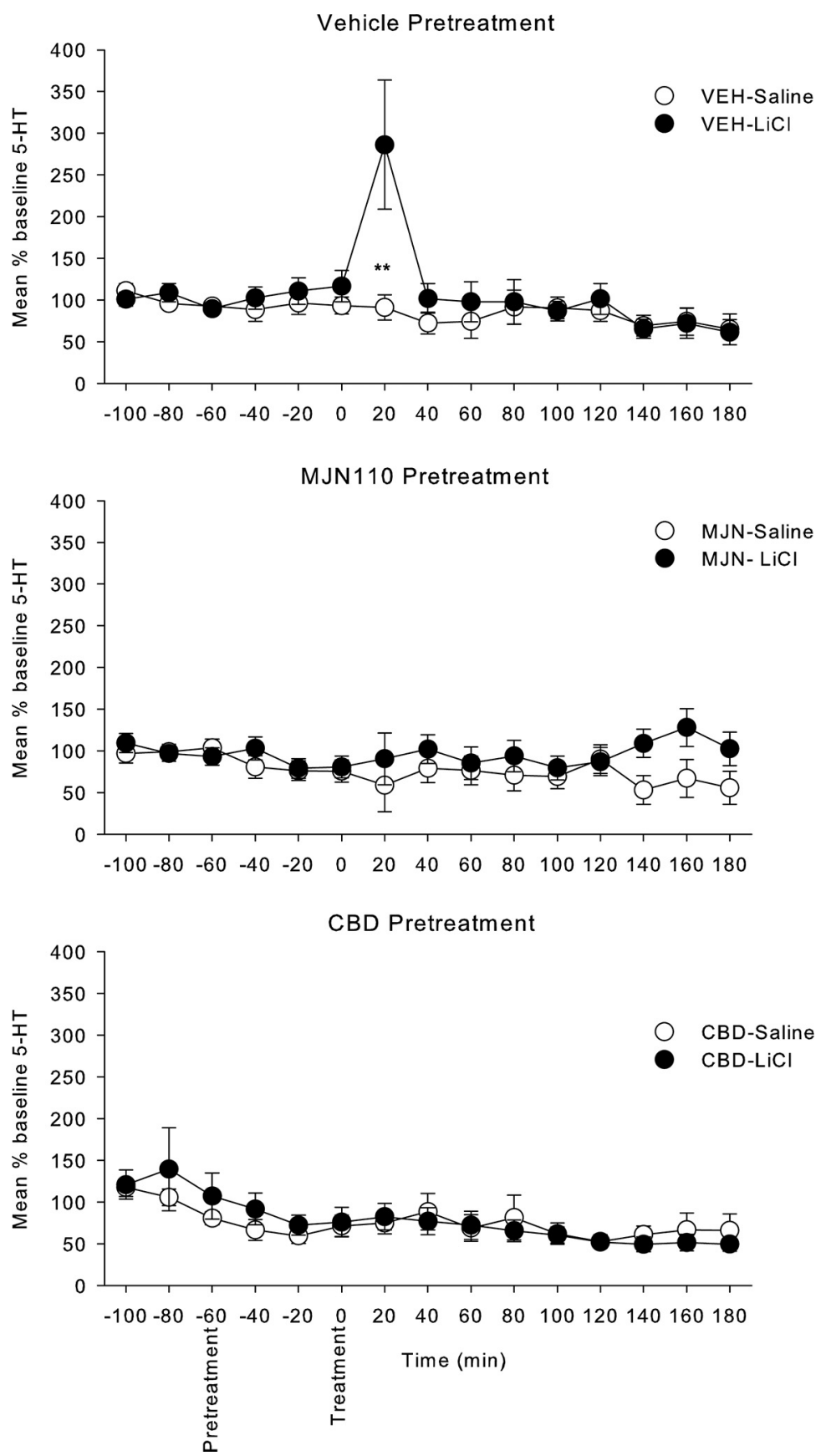

Figure 3. Mean ( \pm SEM) \% baseline 5-HT in rats with microdialysis probes placed in the IIC. Following the initial three baseline measures, the rats were injected intraperitoneally with VEH, MJN110 (10 mg/kg), or CBD (5 mg/kg) followed 60 min later with LiCl or saline. Stars indicate a significant difference between $\mathrm{LiCl}$ and saline, $* * p<0.025$.

separate $2 \times 15$ ANOVAs for the treatment condition for each pretreatment condition separately (as depicted in Fig. 3). For the VEH pretreatment group, there was a significant main effect of time, $F_{(14,252)}=5.2 ; p<0.001$, and a treatment by time interaction, $F_{(14,252)}=4.1 ; p<$ 0.001 , with group $\mathrm{LiCl}$ displaying higher levels than group saline only during the first $20 \mathrm{~min}$ following $\mathrm{LiCl}$ treatment $(p<0.025)$. For the MJN110 pretreatment group, the $2 \times$ 15 ANOVA revealed no significant effects, with $\mathrm{LiCl}$ and saline groups not differing at any interval of testing. For the CBD pretreatment group, the mixed factor ANOVA only revealed a significant main effect of time, $F_{(14,238)}$, with $5-\mathrm{HT}$ levels decreasing across the test overall, but this factor did not interact with the treatment condition.

\section{Experiment 2: effect of MJN110 or ondansetron in the IIC on conditioned gaping elicited by IIC infusion of $5-\mathrm{HT}_{3}$ receptor agonist $\mathrm{mCPBG}$}

The mean number of gapes displayed between the groups across all trials can be seen in Figure 4. Pretreatment with the $5-\mathrm{HT}_{3}$ receptor antagonist OND, but not with MJN110, prevented a conditioned gaping re- 


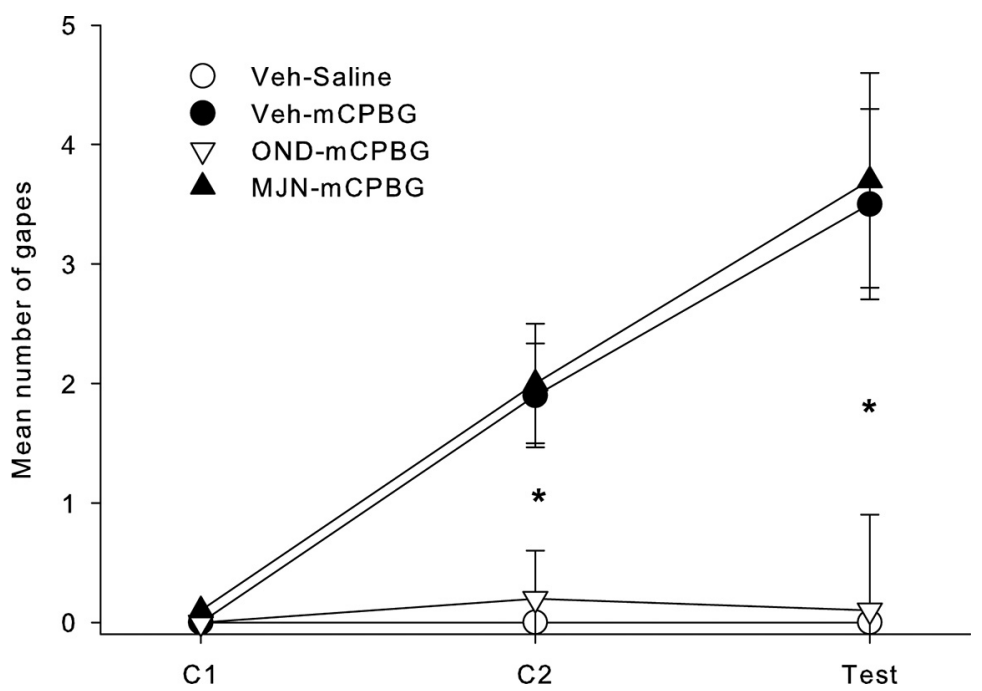

Figure 4. Mean $( \pm$ SEM) number of gapes displayed by rats in the various groups in experiment 2. Stars indicate a significant difference at $* p<0.05$.

sponse that is produced by the $5-\mathrm{HT}_{3}$ receptor agonist mCPBG. The $3 \times 4$ mixed factor ANOVA with the between groups factor of group and within groups factor of trial revealed a significant main effect of group, $F_{(3,34)}=9.4$; $p<0.001$, trial $F_{(2,68)}=13.0 ; p=0.001=$, and a group by trial interaction $F_{(6,68)}=4.1 ; p<0.001$. Single factor ANOVAs revealed a significant main effect of group in the second conditioning trial $F_{(3,34)}=6.3 ; p=0.002$, and test trial $F_{(3,34)}=6.3 ; p=0.002$; subsequent Tukey HSD tests revealed that on both $\mathrm{C} 2$ and the test trial, groups VEH-mCBG and MJN-mCPBG gaped significantly more than either group VEH-saline or ONDmCPBG (ps < 0.05).

\section{Experiment 3: conditioned release of 5-HT in IIC}

Rats exposed to $\mathrm{LiCl}$-paired saccharin displayed higher levels of 5-HT release during the saccharin exposure period than rats exposed to saline-paired saccharin. Figure 5 presents the mean $( \pm$ SEM) percentage of baseline 5-HT during each sampling interval among the rats exposed to saccharin previously paired with $\mathrm{LiCl}$ or saline. The $2 \times 15$ mixed factors ANOVA revealed only a significant group $\times$ time interaction, $F_{(14,154)}=2.04 ; p=0.018$. Subsequent $t$ tests revealed that group Sac- $>\mathrm{LiCl}$ showed elevated $5-\mathrm{HT}$ relative to group Sac- $>$ saline during the 20 min taste reactivity test trial $(p<0.01)$, only. Table 1 presents the mean ( \pm SEM) number of gapes and

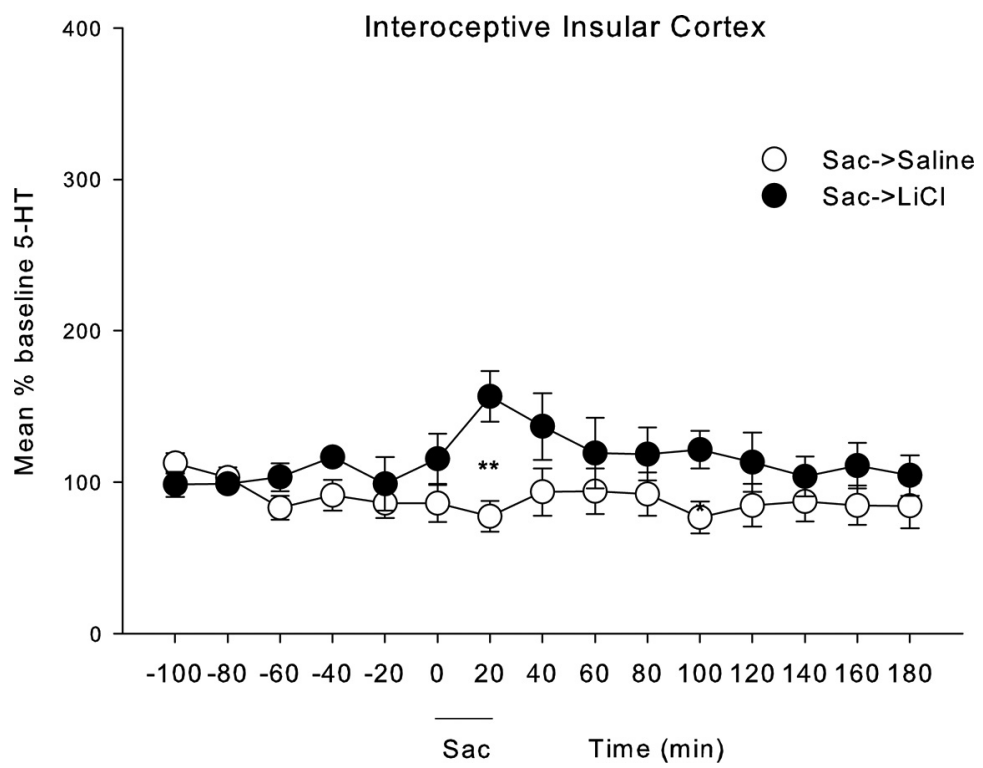

Figure 5. Mean ( \pm SEM) \% baseline 5-HT in rats with microdialysis probes placed in the IIC over the 300 min of sample collection every $20 \mathrm{~min}$. The first six measures served as baseline measures which were used to convert each score into a \% baseline measure. Following the final baseline measure, the rats were intraorally infused with saccharin for 20 min, and samples continued to be collected for the remainder of the 300-min session. Stars indicate a significant difference at $* * * p<0.01$. 
Table 1. Mean ( \pm SEM) number of gapes and seconds of activity displayed by the $\mathrm{LiCl}$ and saline conditioned groups during the 20-min infusion of saccharin solution in the microdialysis chamber in experiment 3

\begin{tabular}{llc}
\hline & \multicolumn{1}{c}{ Gapes } & Activity (s) \\
Saline & $0.0(+0.00)$ & $130.83(+33.46)$ \\
$\mathrm{LiCl}$ & $45.43( \pm 7.33)^{* * * *}$ & $158.00( \pm 36.38)$
\end{tabular}

${ }^{* * * *} p<0.01$

sec of general activity (active locomotion + rearing) displayed during the 20 min sampling period in the microdialysis chambers. As is apparent, the LiCl conditioned rats gaped more to the saccharin infusion than the saline conditioned rats (which did not gape), $t_{(11)}=5.705 ; p<$ 0.001 . The groups did not differ in overall general activity level, $t_{(11)}=0.598 ; p>0.05$.

\section{Discussion}

$\mathrm{LiCl}$, but not equivolume injections of saline, elicited an elevation of 5-HT in the IIC, but not in the adjacent GIC. This elevated $5-\mathrm{HT}$ was prevented by pretreatment with the MAGL inhibitor, MJN110, or with the $5-\mathrm{HT}_{1 \mathrm{~A}}$ receptor agonist, CBD. Since intracranial administration of MJN110 into the IIC prevents $\mathrm{LiCl}$-induced conditioned gaping reactions (Sticht et al., 2016), these results suggest that the suppression of nausea by MJN110 is mediated by its reduction of $\mathrm{LiCl}$-induced release of $5-\mathrm{HT}$ in this region. These results are consistent with reports that selective 5-HT lesions (with 5,7-DHT) in the IIC, but not the GIC, prevent $\mathrm{LiCl}$-induced conditioned gaping reactions (Tuerke et al., 2012a). As well, administration of the $\mathrm{CB}_{1}$ receptor agonist, HU-210, into the IIC, but not the GIC, reduces $\mathrm{LiCl}$-induced gaping reactions (Limebeer et al., 2012). Both the central effects of MJN110 and HU-210 are $\mathrm{CB}_{1}$ receptor mediated, because their anti-nausea effect is prevented by pretreatment with the $\mathrm{CB}_{1}$ receptor antagonist, AM251 (Limebeer et al., 2012; Sticht et al., 2016). CBD acts as a somatodendritic 5- $\mathrm{HT}_{1 \mathrm{~A}}$ autoreceptor agonist in the dorsal raphe nucleus to reduce LiClinduced conditioned gaping in rats (Rock et al., 2012). Within this region, $5-\mathrm{HT}_{1 \mathrm{~A}}$ receptor agonists, such as $8-\mathrm{OH}-\mathrm{DPAT}$, reduce the firing rate of $5-\mathrm{HT}$ afferents thereby reducing the release of $5-\mathrm{HT}$ in terminal regions (Verge et al., 1985; Blier and de Montigny, 1987). Therefore, the suppression of nausea by CBD appears to be mediated by its reduction of $\mathrm{LiCl}$-induced $5-\mathrm{HT}$ in the IIC.

The $\mathrm{LiCl}$-induced elevation of $5-\mathrm{HT}$ in the IIC is the presumed trigger for the sensation of nausea. However, it is also possible that $5-\mathrm{HT}$ is elevated in the IIC as a response to nausea induced behaviours displayed by the rat during the experience with $\mathrm{LiCl}$. It is unlikely that the elevated $5-\mathrm{HT}$ is the result of context- $\mathrm{LiCl}$ associations, given that the rats did not have any prior experience with $\mathrm{LiCl}$ in the context of the microdialysis chambers. As well, it is unlikely that the elevated $5-\mathrm{HT}$ is due to the rats experiencing something aversive (not nausea per se), because (1) only drugs that produce emesis in other species produce conditioned gaping in rats (Parker 2014), (2) drugs which reduce 5- $\mathrm{HT}$ release [e.g., $\mathrm{HT}_{1 \mathrm{~A}}$ agonists, CBD (Rock et al., 2012), and 8-OH-DPAT (Limebeer and
Parker, 2003)] prevent LiCl-induced conditioned gaping in rats, (3) selective 5-HT lesions in the IIC prevent $\mathrm{LiCl}-$ induced conditioned gaping in rats (Tuerke et al., 2012a), (4) elevation of 2-AG in the IIC prevents $\mathrm{LiCl}$-induced conditioned gaping in rats (Sticht et al., 2016) and reduces the elevated serotonin release in this region (data reported here). These all suggest that it is not an aversive event per se that produced the elevated $5-\mathrm{HT}$ in the IIC, but the selective aversive event of a nauseating experience.

Although MJN110 reduces LiCl-induced conditioned gaping when delivered systemically (Parker et al., 2015) or intracranially into the IIC (Sticht et al., 2016), IIC administration of MJN110 did not prevent conditioned gaping produced by intracranial administration of the postsynaptic $5-\mathrm{HT}_{3}$ receptor agonist, $\mathrm{mCPBG}$. On the other hand, the postsynaptic $5-\mathrm{HT}_{3}$ receptor antagonist, ondansetron administered to the IIC did prevent MCPG induced conditioned gaping as has been reported by Tuerke et al., 2012a). These results provide further support that the regulation of nausea by 2-AG in the IIC is via its action on presynaptic $\mathrm{CB}_{1}$ receptors which act to "turn off" the release of $5-\mathrm{HT}$ from terminal endings. They further suggest that $\mathrm{LiCl}$ produces nausea by elevating $5-\mathrm{HT}$ release in the IIC which in turn acts on postsynaptic $5-\mathrm{HT}_{3}$ receptors in this region.

Not only did the unconditional nausea inducing agent, $\mathrm{LiCl}$, produce elevation of $5-\mathrm{HT}$ in the IIC, exposure to a $\mathrm{LiCl}$-paired saccharin cue produced a conditional elevation of 5-HT in the IIC during the 20-min intraoral infusion while rats displayed the nausea-induced behavior of conditioned gaping. These results provide evidence that conditioned nausea is also produced by elevation of $5-\mathrm{HT}$ in this region.

Although elevation of 2-AG in the IIC by MAGL inhibition reduced $\mathrm{LiCl}$-induced conditioned gaping in rats, Sticht et al. (2016) found that fatty acid amide hydrolase (FAAH) inhibition in the IIC did not prevent LiCl-induced conditioned gaping. Indeed, FAAH inhibition in the IIC did not elevate $A E A$ in this region, although it did elevate other fatty acids, oleoyl ethanolamide (OEA) and palmitoyl ethanolamide (PEA), which are also degraded by FAAH. These results suggest that the endogenous cannabinoid that regulates nausea within this brain region is 2-AG, not $A E A$. On the other hand, FAAH inhibition has been found to reduce $\mathrm{LiCl}$-induced nausea when administered systemically (Rock et al., 2015; Parker et al., 2016). This effect may be mediated by a peripheral mechanism, since Rock et al. (2017) found that the peripherally restricted FAAH inhibitor, URB937, reduced $\mathrm{LiCl}$-induced conditioned gaping, potentially by its action on the area postrema, an area of weakened blood brain barrier. Future research needs to address potential central sites of action of FAAH inhibition in the reduction of nausea.

Despite its prevalence, the treatment of nausea has lagged behind the treatment of vomiting. There is a pressing need to treat this distressing symptom. The results of these experiments provide a greater understanding of the neuroanatomical and neurochemical basis of nausea, and may be useful in identifying new treatments that act to 
reduce nausea-induced $5-\mathrm{HT}$ release either by boosting the eCB system or by reducing IIC release of $5-\mathrm{HT}$.

\section{References}

Allen GV, Saper CB, Hurley KM, Cechetto DF (1991) Organization of visceral and limbic connections in the insular cortex of the rat. $J$ Comp Neur 311:1-16. CrossRef Medline

Ballatori E, Roila F, Ruggeri B, Betti M, Sarti S, Soru G, Cruciani G, Di Maio M, Andrea B, Deuson RR (2007) The impact of chemotherapy-induced nausea and vomiting on health-related quality of life. Support Care Cancer 15:179-185. CrossRef Medline

Blier P, de Montigny C (1987) Modification of 5-HT neuron properties by sustained administration of the $5-\mathrm{HT} 1 \mathrm{~A}$ agonist gepirone: electrophysiological studies in the rat brain. Synapse 1:470-480. CrossRef Medline

Bolognini D, Rock EM, Cluny NL, Cascio MG, Limebeer CL, Duncan M, Stott CG, Javid FA, Parker LA, Pertwee RG (2013) Cannabidiolic acid prevents vomiting in Suncus murinus and nauseainduced behaviour in rats by enhancing $5-\mathrm{HT} 1 \mathrm{~A}$ receptor activation. Br J Pharmacol 168:1456-1470. CrossRef Medline

Calder AJ, Keane J, Manes F, Antoun N, Young AW (2000) Impaired recognition and experience of disgust following brain injury. Nat Neurosci 3:1077-1078. CrossRef Medline

Calder AJ, Lawrence AD, Young AW (2001) Neuropsychology of fear and loathing. Nat Rev Neurosci 2:352-363. CrossRef Medline

Cechetto DF, Saper CB (1987) Evidence for a viscerotopic sensory representation in the cortex and thalamus in the rat. J Comp Neur 262:27-45. CrossRef Medline

Contreras M, Ceric F, Torrealba F (2007) Inactivation of the interoceptive insula disrupts drug craving and malaise induced by lithium. Science 318:655-658. CrossRef Medline

Foubert J, Vaessen G (2005) Nausea: the neglected symptom? Eur J Oncol Nurs 9:21-32. CrossRef Medline

Garcia J, Hankins WG, Rusiniak KW (1974) Behavioral regulation of the milieu interne in man and rat. Science 185:824-831. Medline

Grill HJ, Norgren R (1978) The taste reactivity test. I. Mimetic responses to gustatory stimuli in neurologically normal rats. Brain Res 143:263-279. Medline

Hamilton RB, Norgren R (1984) Central projections of gustatory nerves in the rat. J Comp Neur 222:560-577. CrossRef Medline

Häring M, Marsicano G, Lutz B, Monory K (2007) Identification of the cannabinoid receptor type 1 in serotonergic cells of raphe nuclei in mice. Neuroscience 146:1212-1219. CrossRef Medline

Häring M, Grieb M, Monory K, Lutz B, Moreira FA (2013) Cannabinoid $\mathrm{CB}(1)$ receptor in the modulation of stress coping behavior in mice: the role of serotonin and different forebrain neuronal subpopulations. Neuropharmacology 65:83-89. CrossRef Medline

Hermann H, Marsicano G, Lutz B (2002) Coexpression of the cannabinoid receptor type 1 with dopamine and serotonin receptors in distinct neuronal subpopulations of the adult mouse forebrain. Neuroscience 109:451-460. Medline

Hickok JT, Roscoe JA, Morrow GR, King DK, Atkins JN, Fitch TR (2003) Nausea and emesis remain significant problems of chemotherapy despite prophylaxis with 5-hydroxytryptamine-3 antiemetics: a University of Rochester James P. Wilmot Cancer Center Community Clinical Oncology Program Study of 360 cancer patients treated in the community. Cancer 97:2880-2886. CrossRef

Kiefer SW, Orr MR (1992) Taste avoidance, but not aversion, learning in rats lacking gustatory cortex. Behav Neurosci 106:140-146. Medline

Kosar E, Grill HJ, Norgren R (1986) Gustatory cortex in the rat. I. Physiological properties and cytoarchitecture. Brain Res 379:329341. Medline

Limebeer CL, Parker LA (2003) The 5-HT1A agonist 8-OH-DPAT dose-dependently interferes with the establishment and the ex- pression of lithium-induced conditioned rejection reactions in rats. Behav Neurosci 117:105-112.

Limebeer CL, Rock EM, Mechoulam R, Parker LA (2012) The antinausea effects of CB1 agonists are mediated by an action at the visceral insular cortex. Br J Pharmacol 167:1126-1136. CrossRef Medline

Napadow V, Sheehan JD, Kim J, Lacount LT, Park K, Kaptchuk TJ, Rosen BR, Kuo B (2013) The brain circuitry underlying the temporal evolution of nausea in humans. Cereb Cortex 23:806-813. CrossRef Medline

Parker LA (2014) Conditioned flavor avoidance and conditioned gaping: rat models of conditioned nausea. Eur J Pharmacol 722: 122-133. CrossRef

Parker LA, Niphakis MJ, Downey R, Limebeer CL, Rock EM, Sticht MA, Morris H, Abdullah RA, Lichtman AH, Cravatt BF (2015) Effect of selective inhibition of monoacylglycerol lipase (MAGL) on acute nausea, anticipatory nausea, and vomiting in rats and Suncus murinus. Psychopharmacology 232:583-593. CrossRef Medline

Parker LA, Limebeer CL, Rock EM, Sticht MA, Ward J, Turvey G, Benchama O, Rajarshi G, Wood J, Alapafuja SO, Makriyannis A (2016) A comparison of a novel MAGL and dual FAAH/MAGL inhibitor to suppress acute and anticipatory nausea in rodent models. Psychopharmacology (Berl) 233:265-75. CrossRef

Penfield W, Faulk ME (1955) The insula; further observations on its function. Brain 78:445-470. Medline

Rock EM, Bolognini D, Limebeer CL, Cascio MG, Anavi-Goffer S, Fletcher PJ, Mechoulam R, Pertwee RG, Parker LA (2012) Cannabidiol, a non-psychotropic component of cannabis, attenuates vomiting and nausea-like behaviour via indirect agonism of $5-\mathrm{HT}(1 \mathrm{~A})$ somatodendritic autoreceptors in the dorsal raphe nucleus. Br J Pharmacol 165:2620-2634. CrossRef Medline

Rock EM, Limebeer CL, Ward JM, Cohen A, Grove K, Niphakis MJ, Cravatt BF, Parker LA (2015) Interference with acute nausea and anticipatory nausea in rats by fatty acid amide hydrolase (FAAH) inhibition through a PPAR $\alpha$ and CB1 receptor mechanism, respectively: a double dissociation. Psychopharmacology (Berl) 232: 3841-3848. CrossRef Medline

Rock EM, Moreno-Sanz G, Limebeer CL, Petrie GN, Angelini R, Piomelli D, Parker LA (2017) Suppression of acute and anticipatory nausea by peripherally restricted fatty acid amide hydrolase inhibitor in animal models: role of PPAR $\alpha$ and $\mathrm{CB} 1$ receptors. $\mathrm{Br} \mathrm{J}$ Pharmacol 174:3837-3847. CrossRef Medline

Sclocco R, Kim J, Garcia RG, Sheehan JD, Beissner F, Bianchi AM, Cerutti S, Kuo B, Barbieri R, Napadow V (2016) Brain circuitry supporting multi-organ autonomic outflow in response to nausea. Cereb Cortex 26:485-497. CrossRef Medline

Sticht MA, Limebeer CL, Rafla BR, Abdullah RA, Poklis JL, Ho W, Niphakis MJ, Cravatt BF, Sharkey KA, Lichtman AH, Parker LA (2016) Endocannabinoid regulation of nausea is mediated by 2-arachidonoylglycerol (2-AG) in the rat visceral insular cortex. Neuropharmacology 102:92-102. CrossRef Medline

Tuerke KJ, Limebeer CL, Fletcher PJ, Parker LA (2012a) Double dissociation between regulation of conditioned disgust and taste avoidance by serotonin availability at the $5-\mathrm{HT}(3)$ receptor in the posterior and anterior insular cortex. J Neurosci 32:13709-13717. CrossRef

Tuerke KJ, Winters BD, Parker LA (2012b) Ondansetron interferes with unconditioned lying-on belly and acquisition of conditioned gaping induced by $\mathrm{LiCl}$ as models of nausea-induced behaviors in rats. Physiol Behav 105:856-860. CrossRef

Verge D, Daval G, Patey A, Gozlan H, el Mestikawy S, Hamon M (1985) Presynaptic 5-HT autoreceptors on serotonergic cell bodies and/or dendrites but not terminals are of the $5-\mathrm{HT} 1 \mathrm{~A}$ subtype. Eur J Pharmacol 113:463-464. CrossRef

Zalaquett C, Parker LA (1989) Further evidence that CTAs produced by lithium and amphetamine are qualitatively different. Learn Motiv 20:413-427. CrossRef 